\title{
PÓS-TRATAMENTO DE LIXIVIADO DO ATERRO SANITÁRIO DE CIANORTE-PR POR FILTRAÇÃO ASCENDENTE EM PEDREGULHO SEGUIDA DE ADSORÇÃO EM CARVÃO ATIVADO GRANULAR
}

\author{
Andressa Algayer da Silva ${ }^{1}$
}

Renan Borelli Galvão ${ }^{2}$

Vilson Gomes da Assunção Júnior ${ }^{3}$

\begin{abstract}
RESUMO
A forma de disposição de resíduos sólidos urbano mais usual no Brasil atualmente é em aterros sanitários. Isto ocasionou a geração de dois principais subprodutos: os gases e o lixiviado. Devido suas características este liquido de coloração escura deve receber um tratamento adequando antes do lançamento em corpo hídrico. Logo, o objetivo deste trabalho foi avaliar a eficiência do pós-tratamento de lixiviado de aterro sanitário por coagulação, filtração ascendente em pedregulho seguido de adsorção em carvão ativado granular em instalação piloto de escoamento contínuo em relação à remoção de matéria orgânica recalcitrante. Para isto foi coletado o lixiviado tratado biológico do aterro sanitário de Cianorte-PR e foi utilizado a instalação piloto do filtro ascendente em pedregulho dimensionado por Fujii (2013), seguido da coluna de carvão ativado nas dimensões $4 \times 4 \mathrm{~cm}$ de base e $45 \mathrm{~cm}$ de altura, com dosagem de cloreto férrico de $100 \mathrm{mg} \mathrm{L}^{-1} \mathrm{em} \mathrm{pH} 4$ previamente determinadas em Jarteste. Para estas instalações obtiveram-se remoções de cor aparente e verdadeira de $100 \%$ e turbidez de $98,6 \%$. Pode-se verificar com este experimento a eficiência do sistema para remoções de características recalcitrantes. Contudo ainda são necessários estudos posteriores para avaliar as remoções dos demais parâmetros contidos em legislações vigentes.
\end{abstract}

PALAVRAS-CHAVE: Lixiviado. Filtração Ascendente em Pedregulho. Carvão Ativado Granular.

\footnotetext{
${ }^{1}$ Mestranda em Engenharia de Edificações e Saneamento, Universidade Estadual de Londrina. andressa_algayer@hotmail.com

${ }^{2}$ Discente do curso de Engenharia Civil, Universidade Estadual de Londrina. renan_bg7th@msn.com

${ }^{3}$ Mestrando em Engenharia de Edificações e Saneamento, Universidade Estadual de Londrina. vilsonvgaj@msn.com
} 


\title{
POST-TREATMENT OF LANDFILL LEACHED CIANORTE-PR UPWARD FLOW SAND FILTRATION FOLLOWED BY ADSORPTION ON GRANULAR ACTIVATED CARBON
}

\begin{abstract}
The domestic solid waste in Brazil is currently disposed into landfills. This led to the generation of two main byproducts, gases and leachate. Due to its characteristics, this dark colored liquid should receive proper treatment before release into the water body. Therefore, the aim of this study was to evaluate the efficiency of the posttreatment of landfill leachate by coagulation, upward flow sand filtration followed by adsorption on granular activated carbon in a continuous flow pilot plant regarding the removal of refractory organic matter. For this experiment, the biologically treated leachate were collected from the landfill Cianorte-PR, the upward flow sand filtration system was same with the one used in Fujii (2013) and following column of activated carbon had $45 \mathrm{~cm}$ height in the dimensions $4 \times 4 \mathrm{~cm}$ base. Ferric chloride dosage was set as $100 \mathrm{mg} \mathrm{L-1}$ to achieve pH4, which had been determined in Jarteste. With these facilities, achieved removal efficiencies of apparent color, true color and turbidity were $100 \%, 100 \%$ and $98.6 \%$, respectively. It is possible check the efficiencies of this experimental system to removal refractory organic matter. However further studies are still required to evaluate the removal efficiency of the remaining parameters included in brasilian regulations.
\end{abstract}

KEY-WORDS: leachate upward flow sand filtration. granular activated carbon.

\section{POST-TRATRAMIENTO DE LIXIVIADO DE RELLENO SANITARIO DE CIANORTE-PR POR FILTRACIÓN ASCENDENTE EN MANTO DE GRAVA SEGUIDO POR ADSORCIÓN CON CARBÓN ACTIVADO GRANULAR}

\begin{abstract}
RESUMEN
La disposición de los residuos sólidos urbanos de costumbre en Brasil se encuentra actualmente en los vertederos. Esto condujo a la generación de dos subproductos principales son gases y lixiviados. Por sus características este líquido de color oscuro debe recibir el tratamiento adecuado antes de su liberación en el cuerpo de agua. Por lo tanto, el objetivo de este estudio fue evaluar la eficacia de la post-tratamiento de los lixiviados de vertedero por coagulación, canto rodado filtración ascendente seguido por adsorción sobre carbón activado granular en un flujo continuo de planta piloto con respecto a la remoción de materia orgánica recalcitrante. Para esto fue el lixiviado tratado biológico recogidos del vertedero Cianorte-PR y el piloto de la roca instalación filtro aguas arriba de tamaño por Fujii (2013), seguido de la columna de carbón activado y las dimensiones se utilizó $4 \times 4 \mathrm{~cm}$ de base y $45 \mathrm{~cm}$ de altura, con dosificación de cloruro férrico de $100 \mathrm{mg} \mathrm{L-1} \mathrm{a} \mathrm{pH} 4$ Jarteste previamente determinada. Para estas instalaciones de eliminación de turbidez aparente y verdadera del color del 100\% y el 98,6\% que ofrece. Usted puede comprobar con este experimento la eficiencia del sistema para la extracción de características recalcitrantes. Sin embargo aún se necesitan más estudios para evaluar la eliminación de los restantes parámetros contenidos en los reglamentos.
\end{abstract}

PALABRAS-CLAVE: lixiviados hacia arriba. filtración de arena de flujo. carbón activado granular. 


\section{INTRODUÇÃO}

O desenvolvimento econômico associado ao crescimento populacional ocasionou uma excessiva geração de resíduos sólidos urbanos no mundo. Os resíduos sólidos quando dispostos inadequadamente causam grandes poluições ambientais. Neste contexto, a Politica Nacional de Resíduos Sólidos instituída pela lei 12.305/2010 incentivou a exclusão de lixões e a implantação de aterros sanitários como uma maneira adequada de disposição final.

Segundo a ABNT NBR 8419/1992 aterros sanitários são definidos como sendo: técnicas de disposição de resíduos sólidos urbanos no solo, o qual utiliza métodos de engenharia para confinar estes resíduos à menor área possível e reduzilo ao menor volume permissível cobrindo-os com uma camada de terra na conclusão de cada jornada de trabalho, ou a intervalos menores, se necessário. Logo, os aterros sanitários devem ser implantados e operacionalizados de maneira a evitar a contaminação das águas subterrâneas, solo e atmosfera pelo lixiviado e liberação de gases tóxicos.

No aterro sanitário, a biodegradação dos resíduos sólidos ocorre através de processos físicos, químicos e biológicos, produzindo subprodutos como os gases e o lixiviado (chorume). O lixiviado é um líquido de coloração escura, com elevados teores de turbidez, e com odor desagradável.

O lixiviado apresenta composição variável e complexa com alto poder de toxicidade, podendo variar de acordo com as condições climáticas, idade do aterro, precipitação, entre outros. Em sua composição podem ser encontradas altas concentrações de matéria orgânica biodegradável e refratária, compostos nitrogenados e traços de metais pesados (WISZNIOWSKI et al., 2006), além de diferentes microrganismos.

A biodegrabilidade do lixiviado varia com a idade do aterro e pode ser verificada através da relação DBO5/DQO. No início da decomposição, esta relação é igual ou maior a 0,5 sendo que a faixa de 0,4 à 0,6 indica que a matéria orgânica presente no lixiviado é altamente biodegradável. Em aterros "antigos" a relação 
encontra-se entre 0,05 a 0,2. A razão é menor devido à presença de ácidos fúlvicos e húmicos, que não são facilmente biodegradáveis (TCHOBANOGLOUS, THEISEN \& VIGIL, 1993 apud FERREIRA, 2010), conferindo característica recalcitrante ao lixiviado.

Renou et al., (2007) aponta em seu estudo que os principais parâmetros para representar o lixiviado de aterros sanitários são DQO, DBO, a relação DBO / DQO, $\mathrm{pH}$, sólidos em suspensão (SS), nitrogênio amoniacal (NH3-N), nitrogênio total Kjeldahl (NTK) e metais pesados. A Resolução brasileira 357/2005 e a 430/2008 do Conselho Nacional do Meio Ambiente estabelece condições e padrões de lançamento de efluentes em corpo hídrico o qual compreende, para os principais parâmetros, valores de $\mathrm{pH} 5$ e 9, materiais sedimentáveis $1 \mathrm{~mL} / \mathrm{L}$, nitrogênio amoniacal $20 \mathrm{mg} / \mathrm{L}$ e a Resolução CEMA n ${ }^{0} 086$ de 2013 fixa redução de $80 \%$ da DQO do efluente de entrada. Portanto, tais parâmetros são fundamentais para controlar a poluição que pode ser causada nos corpos hídricos pelos despejos deste efluente.

Logo, devido à complexidade da variabilidade da composição dos lixiviados de aterros sanitários a aplicação de um tratamento eficiente para remoção da carga poluente se mostra um desafio. Morais (2005) afirma que o tratamento de lixiviado por processos isolados mostra-se praticamente impossível, sendo necessária a utilização de sistemas de tratamentos combinados.

O tratamento biológico é considerado um dos métodos mais utilizados no tratamento de lixiviado devido ao baixo custo e facilidade operacional. Porém deve ser aplicado em conjunto com outras técnicas de tratamento, pois além de matéria orgânica, os lixiviados são ricos em material recalcitrante (MASSAI, 2007) cujo tratamento exige processos físico-químicos.

A filtração direta ascendente (FDA) consiste basicamente na passagem de lixiviado previamente coagulado com escoamento contínuo, da base ao topo do filtro, sendo que a retenção do lodo formado ocorre primeiramente nas camadas filtrantes inferiores (maior granulometria) e posteriormente nas camadas superiores com menor granulometria (FUJII, 2014). 
Desde as primeiras utilizações da FDA no século $X X$, houve 0 aperfeiçoamento desta tecnologia o que permitiu um melhor aproveitamento das vantagens inerentes a esta técnica. Entre as vantagens destacam-se as principais sendo: a redução das dimensões da estação de tratamento pela eliminação das unidades de floculação e decantação, redução na quantidade de coagulante utilizado, pois não é necessária a formação de flocos grandes e densos, a filtração ocorre no sentido ascensional do grão maior para o menor, utilizando a altura total do meio filtrante para a retenção de impurezas e redução da perda de carga durante a filtração em decorrência da remoção de uma quantidade substancial de impurezas na porção do meio filtrante de maior granulometria (DI BERNARDO e DANTAS, 2005).

A filtração direta ascendente vem sendo muito estudada no tratamento de água para abastecimento humano, porém alguns estudos demonstram que com a utilização de granulometrias adequadas e a realização de descargas de fundo intermediárias, o sistema pode suportar cargas mais elevadas de sólidos (DI BERNARDO, 2003).

Outra alternativa de tratamento físico-químico para efluentes é a aplicação do carvão ativado granular como uma forma de polimento ao pós tratamento de lixiviado. Os carvões são materiais carbonáceos que podem ser de origem animal, vegetal ou mineral e possuem como principal característica a propriedade adsortiva. Em geral, os carvões ativados podem se apresentar na forma granular ou em pó. Quando em pó possuem poros maiores e uma menor superfície interna e quando granular possui grande superfície interna, porém poros menores (BANSAL; DONNET; STOECKLI, 1988).

O objetivo deste trabalho foi avaliar a eficiência do pós-tratamento de lixiviado de aterro sanitário por coagulação, filtração ascendente em pedregulho seguido de adsorção em carvão ativado granular em instalação piloto de escoamento contínuo em relação à remoção de matéria orgânica recalcitrante. 


\section{DESENVOLVIMENTO}

\subsection{Material e métodos}

O lixiviado foi proveniente do aterro sanitário de Cianorte - PR, que encontrase em operação desde o ano de 2002 apresentando assim, características de lixiviado estabilizado. $\mathrm{O}$ tratamento no aterro sanitário é realizado por processos biológicos de lodos ativados e lagoa de maturação. Assim, foram coletados aproximadamente 15 $\mathrm{m}^{3}$ de lixiviado da saída da lagoa de maturação, em caminhão tanque previamente limpo e armazenados em tanque de fibra de vidro localizado nas dependências do Laboratório de Saneamento da UEL.

Os lixiviados antes e após tratamentos foram caracterizados de acordo com os parâmetros e métodos relacionados na Tabela 1.

Tabela 1: Parâmetros e métodos utilizados na caracterização dos lixiviados antes e após tratamentos

\begin{tabular}{|c|c|c|}
\hline \multicolumn{3}{|c|}{ apos tratamentos } \\
\hline Parâmetros & REF. APHA, AWWA, WEF (2005) & Método \\
\hline $\mathrm{pH}\left({ }^{*}\right)$ & Potenciométrico - 4500 & Potenciométrico \\
\hline Alcalinidade & $22320-C$ & Titulométrico \\
\hline N-amoniacal & $4500-\mathrm{NH} 3 \mathrm{~B}$ e $\mathrm{C}$ & Destilação e Titulação \\
\hline Cor verdadeira $\left(^{*}\right)$ & $2120-C$ & $\begin{array}{l}\text { Método espectrofotométrico - } \\
\text { filtrado em membrana } 0,45 \mu \mathrm{m}\end{array}$ \\
\hline Cor Aparente $\left(^{*}\right)$ & $2120-C$ & Método espectrofotométrico \\
\hline Turbidez $\left(^{*}\right)$ & $2130-B$ & Método nefolométrico \\
\hline
\end{tabular}

$\left(^{*}\right)$ : Parâmetros determinados nos efluentes pós-tratados

Foram realizados ensaios de coagulação - floculação - sedimentação em reatores estáticos e escala de bancada - Jarteste a fim de se obter as condições de maior eficiência (dosagem de coagulante e pH de coagulação) em relação à remoção de matéria orgânica recalcitrante, correlacionada à cor verdadeira. Os valores e parâmetros de controle operacional utilizados nos ensaios são apresentados na Tabela 2. 
Tabela 2: Valores e parâmetros de controle operacional - ensaios preliminares

\begin{tabular}{cc}
\hline \multicolumn{2}{c}{ Parâmetros de controle operacional } \\
\hline Tempo médio de mistura rápida (Tmr) & $1 \mathrm{~min}$ \\
Gradiente de velocidade médio de mistura rápida (Gmr) & $600 \mathrm{~s}^{-1}$ \\
Tempo médio de floculação (Tfloc) & $20 \mathrm{~min}^{-1}$ \\
Gradiente de velocidade médio de floculação (Gfloc) & $20 \mathrm{~s}^{-1}$ \\
Velocidade de sedimentação (Vsed) & 0,23 e $0,12 \mathrm{~cm} \mathrm{~min}^{-1}$ \\
Tempo de sedimentação (Tsed) & 30 e $60 \mathrm{~min}$ \\
\hline
\end{tabular}

Os produtos químicos utilizados foram :

- Solução comercial de ácido clorídrico com $37 \%$ em massa e massa específica $=1,187 \mathrm{~kg} \mathrm{~L}^{-1}$ como acidificante;

- Solução comercial de cloreto férrico líquido com $38,94 \%$ de $\mathrm{FeCl}_{3} \cdot 6 \mathrm{H}_{2} \mathrm{O}$, massa específica $=1,412 \mathrm{~kg} \mathrm{~L}^{-1}$ como coagulante.

Os ensaios foram realizados considerando os resultados de trabalhos anteriores obtidos por Kawahigashi (2012); Maler (2013); Pozzetti (2014) e Fujii (2014) e ensaios preliminares, com dosagens de ferro de 100 e $200 \mathrm{mg} \mathrm{L}^{-1} \mathrm{em} \mathrm{pH}$ de 3,5 a 5,5 .

Após determinação das condições de coagulação de maior eficiência, iniciaram-se os ensaios de filtração ascendente em pedregulho e adsorção/filtração em carvão ativado granular em instalação piloto de escoamento contínuo.

A instalação piloto de Filtração Ascendente em Pedregulho foi projetada e construída por Fujii (2014) e encontra-se instalada no Laboratório de Saneamento da Universidade Estadual de Londrina - PR. A composição granulométrica do filtro é apresentada na Tabela 3.

Tabela 3: Composição granulométrica do filtro ascendente em pedregulho em relação à espessura de cada camada

\begin{tabular}{lc}
\hline Composição granulométrica do FAP & Espessura (cm) \\
\hline Areia média $(0,30-1,20 \mathrm{~mm})$ & 60 \\
Areia grossa $(0,6-2,4 \mathrm{~mm})$ & 30 \\
Pedregulho fino $(2,4-4,8 \mathrm{~mm})$ & 30 \\
Pedregulho médio-fino $(4,8-9,5 \mathrm{~mm})$ & 30
\end{tabular}


O sistema de alimentação foi constituído por bombas dosadoras eletromagnéticas (ProMinent - Concept Plus) e mangueiras de sucção em polipropileno que recalcam o lixiviado para a câmara de mistura rápida - CMR que está localizada a uma altura de 6 metros.

O sistema de coagulação química foi composto por câmara de recepção do lixiviado; unidade de dosagem de produtos químicos constituído de bombas dosadoras de coagulante (cloreto férrico) e acidificante (ácido clorídrico) e controlador de $\mathrm{pH}$; câmara de mistura rápida - CMR; e câmara de distribuição de lixiviado coagulado, interligada diretamente ao fundo do filtro a fim de possibilitar a alimentação do mesmo.

A unidade de filtração em carvão ativado granular - FCAG foi instalada em sequência ao filtro ascendente em pedregulho - FAP, sendo construída em acrílico com dimensões de $4 \times 4 \mathrm{~cm}$ de base e $45 \mathrm{~cm}$ de altura. $O$ carvão ativado granular utilizado foi selecionado como de maior eficiência nos estudos de Kawahigashi et al. (2014), e tem como matéria-prima o endocarpo do coco, apresentando número de iodo - NI de $976 \mathrm{mg} \mathrm{g}^{-1}$, e de azul de metileno - IAM de $190 \mathrm{mg} \mathrm{g}^{-1}$.

A taxa de filtração do FAP foi de $15 \mathrm{~m}^{3} \mathrm{~m}^{2}$ dia $^{-1}$ o que correspondeu à vazão de $12 \mathrm{~L} \mathrm{~h}^{-1}$. O lixiviado de saída do FAP foi encaminhado em fluxo contínuo para o FCAG a uma vazão de $2 \mathrm{~L} \mathrm{~h}^{-1}$, resultando em tempo de contato de $20 \mathrm{~min}$.

Durante a operação do FAP foram realizadas 3 descargas de fundo intermediarias - DFI a fim de prolongar o tempo de duração da carreira e uma descarga de fundo final ao atingir $120 \mathrm{~cm}$ de perda de carga no meio granular (critério de encerramento do ensaio do FAP estabelecido). Assim, a primeira DFI foi executada com $30 \mathrm{~cm}$ de perda de carga ( $1^{\circ}$ ciclo), a $2^{\circ} \mathrm{DFI}$ com $60 \mathrm{~cm}$ ( $2^{\circ}$ ciclo), a $3^{\circ}$ DFI com 90 ( $3^{\circ}$ ciclo) e a última descarga de fundo - DF com $120 \mathrm{~cm}$ ( $4^{\circ}$ ciclo), finalizando assim a carreira do FAP e consequentemente do FCAG. 
Para monitoramento e controle da eficiência do sistema foram coletadas amostras nas saídas dos FAP e FCAG a cada 15 minutos na $1^{\text {a }}$ hora, a cada 30 minutos nas $2^{\mathrm{a}}$ e $3^{\mathrm{a}}$ horas e de hora em hora nos demais tempos após partida do sistema.

\subsection{Resultados e discussão}

A Tabela 4 apresenta os valores da caracterização físico-química realizada para o lixiviado tratado biologicamente proveniente do aterro sanitário da cidade de Cianorte - PR.

\begin{tabular}{|c|c|c|}
\hline Parâmetros & Unidade & Tratado Biológico \\
\hline $\mathrm{pH}$ & - & 8,46 \\
\hline Alcalinidade & $\mathrm{mg} \mathrm{CaCO} 3 \mathrm{~L}^{-1}$ & 1293 \\
\hline Turbidez & uT & 242 \\
\hline $\mathrm{N}$-amoniacal & $\mathrm{mg} \mathrm{N}-\mathrm{NH} 3 \mathrm{~L}^{-1}$ & 52 \\
\hline Cor verdadeira & $\mathrm{uH}$ & 658 \\
\hline Cor aparente & $\mathrm{uH}$ & 1419 \\
\hline
\end{tabular}

Quanto aos ensaios preliminares realizados em Jarteste, para determinação das condições de coagulação a serem aplicados nos ensaios em escala piloto, os melhores resultados foram obtidos para dosagem de $100 \mathrm{mg} \mathrm{L}^{-1}$ de $\mathrm{Fe}$ em $\mathrm{pH}$ de coagulação de 4,0 com porcentagem de remoção de cor verdadeira de $100 \%$.

Em seguida, procedeu-se o ensaio de filtração ascendente em pedregulho seguido de adsorção/filtração em carvão ativado granular. Os efluentes produzidos no sistema de filtração ascendente em pedregulho apresentaram valores que variaram entre 0 e $76 \mathrm{uH}$ de cor aparente e entre 0,28 e 5,89 uT de turbidez.

A carreira de filtração do FAP teve duração de 40,67 horas, quando atingiu $120 \mathrm{~cm}$ de perda de carga, caracterizando o encerramento do ensaio de acordo com o critério estabelecido, com consequente interrupção do ensaio de adsorção/filtração em FCAG. 
A Figura 1 apresenta os resultados do monitoramento do sistema de adsorção/filtração em carvão ativado granular em relação à cor aparente e turbidez.

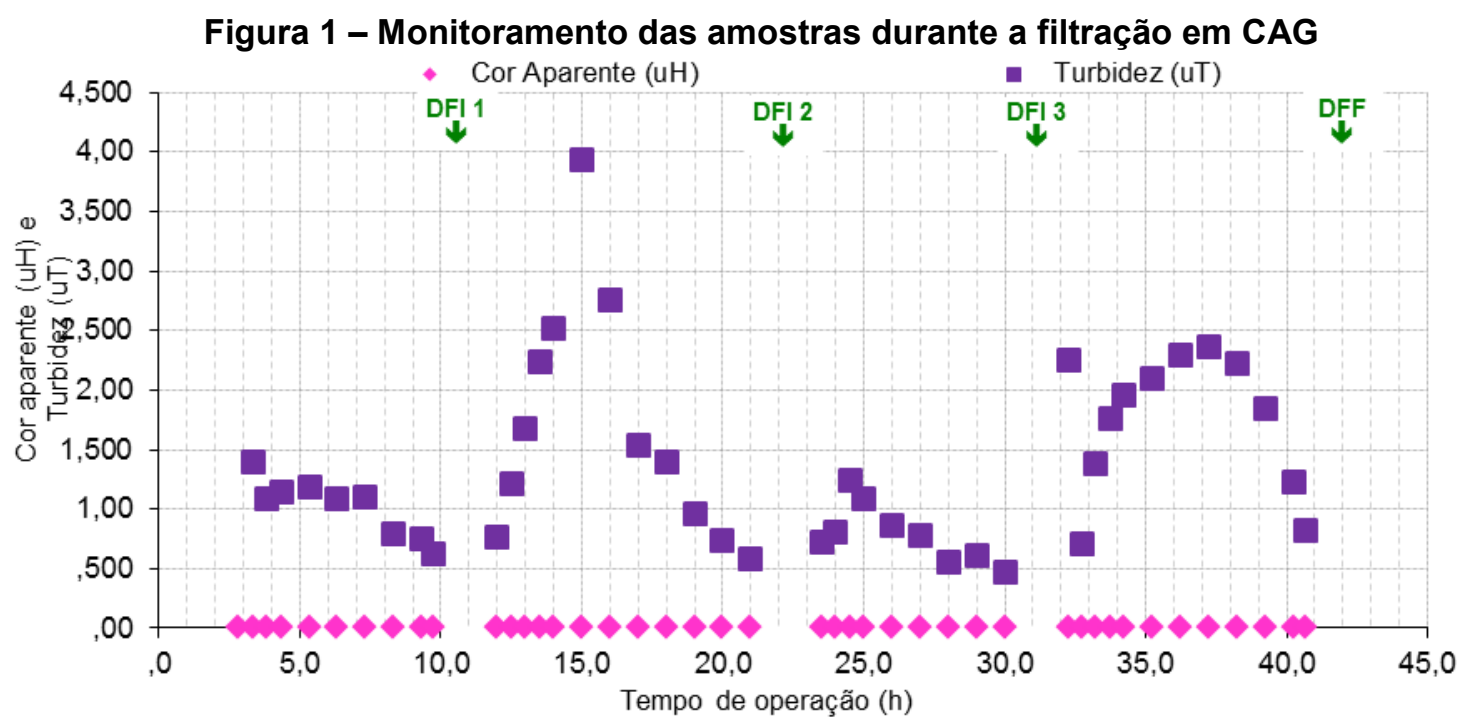

Durante o monitoramento do ensaio de adsorção/filtração em FCAG todos os valores de cor aparente foram nulos e como consequência o parâmetro de cor verdadeira também. Em relação à turbidez os valores mantiveram-se entre de 0,47 e 4,00 uT.

Todo efluente tratado por adsorção/filtração em FCAG foi armazenado em um tanque e ao final de cada ciclo foram coletados $5 \mathrm{~L}$ de amostra devidamente homogeneizada. A amostra global foi composta por alíquotas considerando a proporção relativa ao tempo de operação de cada ciclo. A Figura 2 apresenta os resultados das amostras globais do sistema. 
Figura 2 - Parâmetros físico-químicos em relação às amostras globais

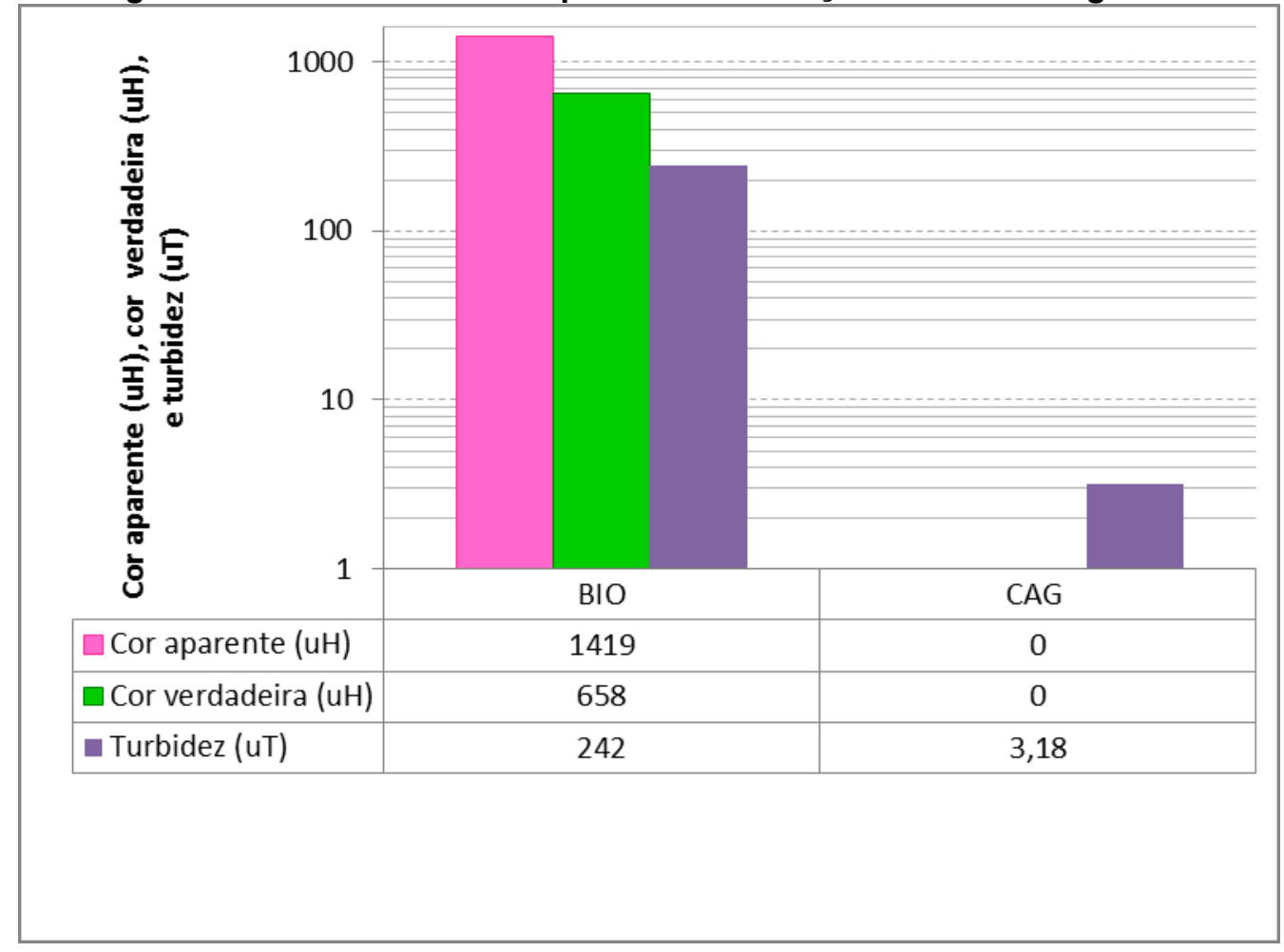

Embora o padrão de lançamento de efluentes da Resolução No 357/2005 CONAMA não estabeleça nenhum valor limite para este parâmetro, vale ressaltar que as condições de enquadramento estabelecidos para águas doces classes 2 e 3 limitam ao valor de cor verdadeira em $75 \mathrm{uH}$.

Para o experimento de adsorção/filtração em FCAG, tanto a remoção de cor aparente quanto de cor verdadeira foram da ordem de $100 \%$ e de para turbidez o valor remanescente foi de 3,18 uT resultando em $98,6 \%$ de remoção, demonstrando a eficiência deste pós-tratamento em relação à matéria orgânica recalcitrante. Existem poucos trabalhos no Brasil e na literatura internacional que apresentam dados a respeito de filtração ascendente em pedregulho e carvão ativado granular para 
tratamentos de efluentes. Fujii et al., (2013) avaliou a filtração ascendente em pedregulho como pós- tratamento de lixiviado estabilizado de Londrina-PR, utilizando como coagulante o cloreto férrico com dosagem de $400 \mathrm{mg} \mathrm{L}^{-1} \mathrm{em} \mathrm{pH} 4$ e taxa de filtração $15 \mathrm{~m}^{3} \mathrm{~m}^{2}$ dia ${ }^{-1}$ obtendo remoção de cor aparente de 99,6\%.

Castilhos Junior et al., (2010) considerou em seu estudo o pré tratamento de lixiviado por filtração direta ascendente - FDA seguido de carvão ativado. As condições experimentais foram previamente adquiridas em escala de bancada em jarteste sendo a dosagem de sulfato de alumínio $900 \mathrm{mg} \mathrm{L}^{-1}$, $\mathrm{pH}$ de coagulação de 7,4 $\pm 0,2$, gradiente de mistura rápida de $800 \mathrm{~s}^{-1}$ e tempo de mistura rápida de $20 \mathrm{~s}$. A taxa de filtração foi de $100 \mathrm{~m}^{3} \mathrm{~m}^{2}$ dia $^{-1}$ com carga hidráulica variável e dosagem de 0,5 $\mathrm{mg} \mathrm{L}^{-1}$ do polieletrólito Tanfloc Pa 0823 . Para o FDA houve uma redução de $89,8 \%$ de cor aparente e quando seguido por filtração em carvão ativado granular - FCA resultou em remoções de cor aparente de $39,2 \%$ do valor de saída do FDA.

\section{CONCLUSÃO}

A filtração ascendente em pedregulho seguida de adsorção em carvão ativado granular mostrou-se eficiente como pós-tratamento de lixiviado estabilizado para remoção de $100 \%$ de cor aparente e cor verdadeira, atendendo às condições de enquadramento estabelecidos pela resolução CONAMA 357/2005 para águas doces classes 2 e 3 que limitam o valor de cor verdadeira em $75 \mathrm{uH}$.

Considerando os resultados obtidos com a filtração ascendente em pedregulho e por Fujii et al., (2013) pôde-se constatar que o pós -tratamento por adsorção/filtração em CAG é capaz de complementar a remoção de matéria orgânica recalcitrante presente em lixiviado estabilizado com características distintas provenientes de aterros sanitários diferentes.,

Porém ainda são necessários estudos complementares em relação aos demais parâmetros de qualidade. 


\section{REFERÊNCIAS}

ASSOCIAÇÃO BRASILEIRA DE NORMAS TÉCNICAS. NBR 8419: Apresentação de projeto de aterros sanitários de resíduos sólidos urbanos. Rio de Janeiro, 1992.

BANSAL, R. C.; DONNET, J. B.; STOECKLI, F. Active Carbon. Marcol Dekker, Inc, New York and Basel, 1988.

BRASIL, Lei N¹2.305 - Institui a Política Nacional de Resíduos Sólidos e dá outras providências. Diário Oficial da União. Brasília, DF, de 2 de agosto de 2010.

BRASIL, Ministério do Meio Ambiente. Conselho Nacional de Meio Ambiente. Resolução No 357, 17 de março de 2005. Dispõe sobre a classificação dos corpos de água e diretrizes ambientais para o seu enquadramento, bem como estabelece as condições e padrões de lançamento de efluentes, e dá outras providências. Brasília, 2005.DI BERNARDO, L. DANTAS, A. D. Métodos e técnicas de tratamento de água. 2 ed. v.1. Rio de Janeiro: ABES, RiMa, 2005.

DI BERNARDO, L. et al. (org.). Tratamento de água para abastecimento por filtração direta. Rio de Janeiro: ABES, 2003. (PROSAB3).

FERREIRA, A. G. Estudos dos lixiviados das frações do aterro sanitário de São Carlos - SP por meio da caracterização físico-química. Dissertação (Mestrado em Ciências) - Escola de Engenharia de São Carlos. Universidade de São Paulo. São Carlos. 2010.

FUJII, E. H. Avaliação da aplicabilidade da filtração direta ascendente em pedregulho como pós tratamento de lixiviado de aterro sanitário. Dissertação (Mestrado em Engenharia de edificações e saneamento). Universidade Estadual de Londrina. Londrina. 2014.

FUJII, E. H. Pós-tratamento de lixiviado de aterro sanitário por filtração direta ascendente em pedregulho. IX Fórum Ambiental da Alta Paulista, v. 9, n. 11, 2013, p.520-535. 2013.

KAWAHIGASHI, F. Aplicabilidade do pós-tratamento de lixiviados de aterro sanitário por adsorção em carvão ativado granular e avaliação ecotoxicológica. 2012. Dissertação (Mestrado em Engenharia de Edificações e Saneamento). Universidade Estadual de Londrina, Londrina, 2012.

MALER, C. L. Aplicação do processo Fenton a diferentes etapas do tratamento de lixiviados de aterro sanitário 2013. Dissertação apresentada ao Programa de Pós-Graduação em Engenharia de Edificações e Saneamento, Universidade Estadual de Londrina, Londrina, 2013.

MASSAI, L. R.; RIBEIRO, C. A.; MASSAI, L. R. D. Tratamento do chorume de aterros sanitários, por precipitação química, com hidróxido de sódio e álcool etílico. $8^{\circ}$ Congresso lberoamericano de Engenharia Mecânica. Pontifícia Universidade Católica de Campinas - PUC. Cusco. 2007.

MORAIS, J. L. Estudo da potencialidade de processos oxidativos avançados, isolados e integrados com processos biológicos tradicionais, para tratamento de chorume de aterro sanitário. Tese (Doutorado em Química). Universidade Federal do Paraná. Curitiba. 2005.

PARANÁ. Conselho Estadual do Meio Ambiente. Resolução 086/2013 - CEMA. Estabelece diretrizes e critérios orientadores para o licenciamento e outorga, projeto, implantação, operação e encerramento de aterros sanitários, visando o controle da poluição, da contaminação e a minimização de seus impactos ambientais e dá outras providências. 
POZZETTI, J. D. C. Pós-tratamento de lixiviado de aterro sanitário por coagulação químicafloculação-sedimentação, adsorção em carvão ativado pulverizado e avaliação ecotoxicológica. 2014. 100 páginas. Dissertação (Mestrado em Engenharia de Edificações e Saneamento) Universidade Estadual de Londrina, Londrina, 2014.

RENOU, S.; GIVAUDAN, J. G.; POULAIN, S.; DYRASSOUYAN, F.; MOULIN P. Landfill leachate treatment: Review and opportunity. Journal of Hazardous Materials. p. 468-493. 2007.

WISZNIOWSKI, J., ROBERT, D., SURMACZ-GORSKA, J., MIKSCH, K., WEBER, J. V. Landfill leachate treatment methods: A review. Environmental Chemistry Letters, v. 4, p.51-61, 2006. 